DOI: $10.21892 / 978-958-5547-66-7.8$

\title{
8. Algunas reflexiones sobre el agua potable y el saneamiento en el marco del derecho a la salud
}

Liliana Páez Jurado ${ }^{3}$

\section{Consideraciones preliminares}

El texto presenta de forma panorámica, y a manera de reflexiones, la evolución y tratamiento en el ordenamiento jurídico del agua y el saneamiento como intereses jurídicos tutelados por el Estado en el marco del derecho a la salud. La finalidad no es otra diferente a la de compilar algunos de los instrumentos más relevantes, con el fin de presentar una perspectiva actual, dada la necesidad acuciante para la especie humana de protegerla, en tanto de su acceso efectivo derivan otros derechos como la salud humana, la alimentación, el desarrollo económico, la igualdad, la justicia y la libertad.

Una primera reflexión nos lleva a considerar el agua como bien social, común e indispensable para todos, encontrándose fuertemente ligado a nuestro patrimonio cultural, tal como lo indican Rodríguez, Lozano y Gómez (2012), citando a la Defensoría del Pueblo:

Un elemento identificador y diferenciador de las culturas.

Este recurso natural está estrechamente relacionado con el patrimonio cultural de la Nación, y su uso y aprovechamiento debe hacerse de conformidad con las costumbres ancestrales y tradicionales, siempre y cuando se respete el medio ambiente y el interés público y social.

Las comunidades a lo largo de la historia han demostrado cómo se desarrollan en torno al auge del agua, su óptimo acceso les permite mantenerse saludables, garantizar la calidad de vida, atender la agricultura, y por supuesto la industria; estrechar relaciones comerciales, así como

3 Abogada de la Universidad Tecnológica de Bolívar. 
Algunas reflexiones sobre el agua potable y el saneamiento en el marco del derecho a la salud

económicas con otras poblaciones, usando los afluentes fluviales y marítimos como canales de navegación.

La Organización Mundial de la Salud (OMS, 2006), en su informe del Decenio del Agua reconoce la presencia del elemento hídrico en cada una de las etapas de la evolución de la humanidad:

El agua es probablemente el único recurso natural que se halla presente en todos los aspectos de la civilización humana, del desarrollo agrícola e industrial a los valores culturales y religiosos inscritos en la sociedad. Desde los albores de la historia de la humanidad, la necesidad y demanda de agua han sido una de las fuerzas motrices en los planos de la salud, la organización social, la prosperidad económica, la trascendencia cultural y el desarrollo.

Este elemento es vital para la naturaleza del ser humano, la interacción con el medio ambiente y la generación de la vida, también fundamental en los procesos internos de los seres vivientes, pues permite el transporte de los nutrientes y conduce el oxígeno a los seres acuáticos. Su proporción dentro del planeta tierra la hace un elemento abundante y necesario para la existencia del mismo, ya que nuestra superficie se encuentra cubierta en 71\% por agua (Guerrero Legarreta, 2012).

El agua se ha convertido en un foco de atención de la agenda mundial, en el informe del Decenio del Agua, publicado por la oficina de las Naciones Unidas, expresan como se han promovido esfuerzos para cumplir los compromisos internacionales que rondan los temas del agua, en el año 2015, el objetivo principal se enmarcó en tratar de elevar el perfil del agua en la agenda global, buscando mayor cooperación entre los gobiernos y otras partes interesadas, entre las naciones y las diversas comunidades, que permita el equilibrio entre los intereses económicos, las necesidades de los ecosistemas y de los pobres, con el ánimo de promover esfuerzos para garantizar la participación de la mujer en la esfera del agua y el saneamiento (Organización de Naciones Unidas -ONU-, 2015a).

Para lo cual, ha sido necesario garantizar el acceso al agua y al saneamiento como derecho humano, constituyendo este, un paso primordial para lograr que sea una realidad para todos, encaminados hacia la obtención segura del preciado recurso y al saneamiento como 
un derecho legal; llegando a aquellos con "peor servicio", con lo cual se intentan disminuir las desigualdades. De igual manera, utilizar los medios y mecanismos disponibles en el sistema de Naciones Unidas en materia de derechos humanos para hacer el seguimiento del progreso de las naciones en la consecución del derecho al agua y al saneamiento básico, procurando el cumplimiento de las responsabilidades de los gobiernos (ONU, 2015b).

Bajo estos presupuestos, el Secretario General de la ONU, Ban KiMoon, sostiene: "Un agua potable segura y un saneamiento adecuado son cruciales para la reducción de la pobreza, para un desarrollo sostenible y para lograr todos y cada uno de los Objetivos de Desarrollo del Milenio" (ONU, 2015).

El agua es un bien común, que merece una protección especial desde todas sus perspectivas, por su trascendencia en el desarrollo individual y como componente necesario para el disfrute de los derechos fundamentales establecidos en nuestra constitución política, porque el progreso de las comunidades depende sustancialmente de este recurso preciado.

Sean estas las razones por las cuales el Estado social de derecho, en cumplimiento de sus fines, de los acuerdos y compromisos internacionales ha de trabajar arduamente orientado hacia la garantía del derecho al agua, especialmente en los sectores oprimidos, que aún tienen necesidades básicas insatisfechas en relación al acceso a fuentes de agua limpia, así como al tratamiento para la evacuación de aguas residuales.

El goce efectivo de este derecho permite una población sana, supera las brechas de desigualdades, contribuye a la disminución de la pobreza y la inclusión social (Rodríguez \& Vargas, 2014), es evidente que todos los sectores del Estado deben trabajar mancomunadamente en este objetivo, pues la falta, tanto de agua para el consumo como de su saneamiento básico, tienen efectos desfavorables sobre la salud, la educación, el trabajo, el medio ambiente, los ingresos, el consumo y especialmente la vida. 
Algunas reflexiones sobre el agua potable y el saneamiento en el marco del derecho a la salud

\section{El derecho al agua potable}

Nuestro planeta está rodeado de fuentes hídricas, no obstante, existen regiones que aún no tienen acceso al agua potable o que a pesar de tener en sus territorios afluentes acuíferas, no pueden hacer uso de ellas, porque se encuentran contaminadas y representan un peligro para su salud.

Para explicar esta idea iniciaremos exponiendo lo que constituye el acceso al agua potable, en términos de la Organización Mundial de la Salud (OMS): "La salubridad y la calidad del agua son fundamentales para el desarrollo y el bienestar humanos. Proporcionar acceso a agua salubre es uno de los instrumentos más eficaces para promover la salud y reducir la pobreza" (OMS, 2017).

En atención a lo antes mencionado podemos indicar que el agua es esencial para la vida y constituye un derecho, por tanto, es prioridad que sea adecuada para el abastecimiento, además, debe contar con los requisitos necesarios para garantizar la salubridad.

Procurando el derecho al agua estamos accediendo a otros derechos fundamentales que deben ser garantizados por el Estado, pues su uso en la producción de alimentos, asegura el derecho a una alimentación adecuada; en la realización de las labores de higiene, su conexidad está dada con el derecho a la vida, a la salud, a la vida con dignidad, y en la búsqueda de los medios de subsistencia, encontramos su vinculación con el derecho al trabajo.

En virtud de su importancia el Comité de Derechos Económicos, Sociales y Culturales ha hecho referencia al derecho que poseemos todos a acceder a este recurso, bajo unas características específicas que propenden a la protección de la salud y de la vida: "(...) el derecho de todos a disponer de agua suficiente, salubre, aceptable, accesible y asequible para el uso personal y doméstico" (ONU, 2002).

Este recurso, como lo expresa el Comité de Derechos Económicos, Sociales y Culturales debe contar con unas características, las cuales permitirán que el ser humano goce de él a plenitud; dentro de ellos hallamos la suficiencia, relativa a la cantidad y a la continuidad que cada individuo necesita para su efectivo goce tanto doméstico como individual; que incluya el agua para beber, el saneamiento personal, la preparación de alimentos, 
la limpieza del hogar y la higiene personal. La OMS ha establecido que una persona por día como mínimo necesita 50 litros de agua para cubrir estas necesidades básicas ${ }^{4}$ (Programa de las Naciones Unidad para el Desarrollo, 2006).

La salubridad es una característica relevante, pues el agua que es apta para el consumo humano debe encontrarse libre de microorganismos, sustancias químicas, hidrocarburos, aceites y peligros radiológicos o cualquier otro elemento que constituyan una amenaza para la salud humana. Las aguas contaminadas están directamente relacionadas con enfermedades como el cólera, las diarreas, la disentería, la hepatitis-A, la fiebre tifoidea y la poliomielitis, en este sentido, la OMS calcula que "unas 842.000 personas mueren cada año de diarrea como consecuencia de la insalubridad del agua" (OMS, 2016).

La aceptabilidad especifica que el agua debe ser inocua y poseer propiedades de color, olor y sabor que no represente ningún peligro y que sean idóneas para el uso personal y doméstico. Las alteraciones de esta característica podrían dar cuenta de contaminantes, químicos naturales, orgánicos e inorgánicos, microorganismos acuáticos, producto de la falta de tratamiento, de un mal almacenamiento o de fallas en la distribución.

La característica que indica que sea físicamente accesible ha sido definida como la cercanía de los servicios de agua, precisando que la fuente de agua debe encontrarse a menos de 1.000 metros del hogar y el tiempo de desplazamiento para la recogida no debería superar los 30 minutos (ONU, 2010).

Lo asequible obedece entonces a la necesidad de que este servicio sea realmente para todos, por eso el Programa de las Naciones Unidas para el Desarrollo (PNUD) ha sugerido que el costo del agua no debería superar

4 Informe Sobre el Desarrollo Humano 2006. Más allá de la escasez: Poder, pobreza y la crisis mundial del agua. Programa de las Naciones Unidad para el Desarrollo. "Las normas internacionales establecidas por organismos como la Organización Mundial de la Salud (OMS) y el Fondo de las Naciones Unidas para la Infancia (UNICEF) sugieren un consumo mínimo de 20 litros al día de una fuente que se encuentre a un kilómetro del hogar. Esta cantidad es suficiente para beber y para la higiene personal básica. Las personas que no acceden a esta cantidad de agua ven limitadas sus capacidades para mantener su bienestar físico y la dignidad que conlleva el estar limpio. Si se consideran las necesidades de agua para el baño y para lavar, aumentaría el límite por persona hasta aproximadamente unos 50 litros diarios". 
Algunas reflexiones sobre el agua potable y el saneamiento en el marco del derecho a la salud

el 3\% de los ingresos del hogar (Programa de las Naciones Unidad para el Desarrollo, 2006).

La Constitución Colombiana no desarrolla el derecho al agua, ni sus características como un derecho individual, sin embargo, el artículo 49 constitucional, consagra la atención de la salud y el saneamiento ambiental como un servicio público a cargo del Estado, y adicionalmente, el artículo 365 reafirma que los servicios públicos son inherentes a la finalidad del Estado Social de Derecho, por lo tanto, el Estado Colombiano está llamado a asegurar la prestación eficiente a todos los habitantes.

Por otra parte, el artículo 79, incluido en el capítulo de los derechos colectivos y del medio ambiente, establece el derecho que tienen todas las personas a gozar de un medio ambiente sano, y el artículo 366, por su parte, indica como finalidades del Estado el bienestar general de la población y el mejoramiento en la calidad de vida.

Para el cumplimiento de lo enunciado en la Carta Magna, es necesario que el recurso hídrico se encuentre presente, pues resulta imprescindible para garantizar el derecho a la vida, así el artículo 11, refiere el derecho a la salud; los artículos 44 y 49, el derecho al trabajo y el artículo 25, el derecho a un ambiente sano, y demás garantías fundamentales constitucionales de los habitantes del territorio nacional.

El artículo constitucional 93 por medio del cual los tratados y convenios internacionales que reconocen derechos humanos, prevalecen en nuestro ordenamiento jurídico, siendo así que el Pacto Internacional de Derechos Económicos, Sociales y Culturales (PIDESC), el cual reconoce el derecho que tienen las personas al disfrute del más alto nivel de su salud física y mental, hace llamado al Estado colombiano a alinear sus políticas hacia la consecución de este derecho para su población. (Pacto Internacional de Derechos Económicos, Sociales y Culturales, 1976)

En el mismo sentido, la Asamblea General de las Naciones Unidas el 28 de julio de 2010, mediante la resolución 64/292, reconoció que el derecho al agua potable y el saneamiento es un derecho humano, exhortando a los Estados y a las organizaciones internacionales a intensificar los esfuerzos para proporcionar un acceso económico y efectivo al agua potable y al saneamiento básico de sus habitantes (ONU, 2010). 
Este derecho -reconocido como derecho humano por el Comité de Derechos Económicos, Sociales y Culturales (CESCR), en virtud de la resolución 1985/17, de 28 de mayo de 1985, del Consejo Económico y Social de las Naciones Unidas (ECOSOC) para desempeñar las funciones de supervisión del Pacto Internacional de Derechos Económicos Sociales y Culturales (PIDESC) - ha constituido un gran reto para todas las naciones, e igualmente ha sido reconocido por su prevalencia en la consecución de una vida digna, permitiendo el disfrute de otros derecho humanos. "El derecho humano al agua es indispensable para vivir dignamente y es condición previa para la realización de otros derechos humanos" (Observación General No. 15. El derecho al agua, 2002).

También la citada resolución de la Asamblea General de la Naciones Unidas, reconoció el derecho humano al agua y al saneamiento, como esenciales para la realización de todos los derechos humanos, precisando la importancia que este representa para el ser humano: "Reconoce que el derecho al agua potable y el saneamiento es un derecho humano esencial para el pleno disfrute de la vida y de todos los derechos humanos" (ONU, 2010).

Aunque ha sido reconocido el acceso al agua potable como un derecho humano en el mundo, aún existen 663 millones de personas sin acceso al agua potable mejorada (OMS \& UNICEF, 2015). También los Objetivos de Desarrollo Sostenible que se pusieron en marcha en el año de 2016 y que orientarán las políticas del Programa de las Naciones Unidas para el Desarrollo (OMS \& UNICEF, 2015), por espacio de 15 años, ha motivado la creación de su sexto objetivo titulado "Agua Limpia y Saneamiento", precisando que:

La escasez de agua afecta a más del 40 por ciento de la población mundial, una cifra alarmante que probablemente crecerá con el aumento de las temperaturas globales producto del cambio climático. Aunque 2.100 millones de personas han conseguido acceso a mejores condiciones de agua y saneamiento desde 1990, la decreciente disponibilidad de agua potable de calidad es un problema importante que aqueja a todos los continentes. En 2011, 41 países experimentaban estrés hídrico; 10 de ellos estaban a punto de agotar su suministro de agua dulce renovable y ahora dependen de fuentes alternativas. El aumento de las 
sequías y la desertificación ya está empeorando estas tendencias. Se estima que al menos una de cada cuatro personas se verá afectada por escasez recurrente de agua para 2050.

Colombia no se escapa a esta problemática, la Encuesta de Calidad de Vida del año 2016, del Departamento Administrativo Nacional de Estadísticas, indica que en promedio 89,6\% de los hogares colombianos cuenta con servicio de acueducto, cuya la cobertura se halla en las cabeceras urbanas en el 97,5\% y en los centros poblados y rurales en el 60,1\%.

El informe del cumplimiento de los Objetivos del Milenio de Colombia publicado en septiembre de 2015 expresó que a pesar de que Colombia fue uno de los países en América Latina, que trabajó arduamente por la consecución de las metas propuestas en la Declaración del Milenio, suscrita 15 años atrás por 189 países miembros de la ONU, logrando avances en las materias propuestas, aún existen muchos retos por cumplir.

El acceso al agua y saneamiento básico, fueron desarrollados en el séptimo objetivo del Milenio que buscaba "garantizar la sostenibilidad del medio ambiente"; las cifras no son muy alentadoras cuando hablamos de las áreas rurales, el campo es el sector con más deficiencia en el acceso a estos servicios, en este sentido, PNUD (2015) explica que:

El $25 \%$ de la población colombiana vive en zona rural, de ellos $47 \%$ no tiene acceso a agua potable y el $94 \%$ no tiene acceso a alcantarillado y saneamiento. (...) La proporción de la población con acceso a métodos de abastecimiento de agua adecuados (conexión a Acueducto) en la zona urbana en 2014 es cercana al $97 \%$ en todo el país. Pese a ello, este indicador exhibe importantes brechas territoriales que merecen atención prioritaria, máxime si se tiene en cuenta que se trata de una necesidad vital básica.

La Corte Constitucional Colombiana desde 1992, ha hecho importantes apuntes con respecto a la trascendencia del agua en la vida de las personas, señalando para ese año que:

El agua constituye fuente de vida y la falta del servicio atenta directamente con el derecho fundamental a la vida de las personas. Así pues, el servicio público domiciliario de acueducto y alcantarillado en tanto que afecte la vida de las personas, la 
salubridad pública o la salud, es un derecho constitucional fundamental y como tal puede ser objeto de protección a través de la acción de tutela. (Corte Constitucional, sentencia T-578/92)

De igual manera la Corte Constitucional ha tutelado el derecho a la vida, por una esencial amenazada en la utilización del agua para consumo humano como necesidad básica, con fundamento en el artículo 366 de la Constitución en el caso específico del Acueducto la "Ciénaga de Tres Esquinas", desagüe del río Bogotá, que se encontraba en construcción y que representó un peligro para la salud de las personas que hacían uso del acueducto (Corte Constitucional, sentencia T-232/93).

Estas primeras sentencias han amparado el derecho al agua potable, en conexidad con el derecho a la vida; posteriormente la Corte Constitucional ha considerado el agua como un derecho fundamental y se ha apropiado de las recomendaciones del Comité de Derechos Económicos, Sociales y Culturales, en el 2002, descritas en la Observación General No. 15, denominado el derecho al agua (Corte Constitucional, sentencia T 740/11).

Precisando que el agua es una necesidad básica, asimismo un elemento indisoluble para la existencia del ser humano. Por tanto, el ordenamiento jurídico colombiano tiene una doble connotación, pues se erige como un derecho fundamental e igualmente como un servicio público. De todos los habitantes del territorio nacional, quienes podrán acceder al servicio de acueducto en condiciones de cantidad y calidad suficientes; el Estado Colombiano está llamado a organizar, dirigir, reglamentar y garantizar su prestación, bajo los principios de eficiencia, universalidad y solidaridad (Corte Constitucional, sentencia T 740/11).

Luego de este pronunciamiento las altas cortes en sus providencias hacen mención al derecho al agua como derecho humano, lo cual permite que este sea tutelado, sin el deber de actuar en conexidad con otros derechos.

\section{El derecho al saneamiento básico}

No solo ha sido reconocido como derecho humano el acceso al agua potable, también lo constituye el saneamiento básico, aunque únicamente es el resultado de compromisos y declaraciones internacionales, entre los que hallábamos los Objetivos de Desarrollo del Milenio, y por supuesto, 
los actuales Objetivos de Desarrollo Sostenible, ya que han asociado estrechamente el saneamiento con el derecho al agua, por ser fundamental para la dignidad humana y la vida digna, además, que asegurando el acceso a este servicio se están protegiendo los recursos existentes de agua potable.

La oficina del Alto Comisionado de las Naciones Unidas para los Derechos Humanos ha indicado al respecto que:

(...) Sin servicios de saneamiento no es posible disfrutar del derecho a una vivienda adecuada. El impacto de la falta de saneamiento en la salud está bien documentado: es responsable de hasta una cuarta parte de las defunciones de menores de 5 años y constituye una grave amenaza al derecho a la salud. El saneamiento deficiente repercute además seriamente en la calidad del agua y pone en peligro también el disfrute de este derecho. (Alto Comisionado de las Naciones Unidas para los Derechos Humanos, 2011).

Y en el año 2006, la Subcomisión de Promoción y Protección de los Derechos Humanos, principal órgano subsidiario de la Comisión de Derechos Humanos, creada en 1947 con 12 miembros e integrada actualmente por 26 expertos independientes en la esfera de los derechos humanos, en desarrollo de sus estudios ha expresado que el saneamiento básico constituye: "El derecho de toda persona a acceder a un servicio de saneamiento adecuado y seguro que proteja la salud pública y el medio ambiente".

El saneamiento básico es vital para la prevención de enfermedades y la salud de las comunidades, la ONU (2010) también se ha referido, concluyendo que:

Todas las personas tienen derecho a un saneamiento seguro y adecuado. Las instalaciones deben situarse donde pueda salvaguardarse la seguridad física de las personas. Garantizar un saneamiento seguro también requiere una educación y promoción sustancial en materia de higiene. Esto significa que las letrinas deben estar disponibles para su uso a cualquier hora del día o de la noche, y deben ser higiénicas; las aguas residuales y las deposiciones deben ser dispuestas de forma segura y se deben construir retretes para prevenir colapsos. 
Por la importancia que este representa para el goce del derecho al agua, es necesario que entremos a precisar este concepto para comprender las actividades que enmarca dentro del Saneamiento Básico: "Se refiere a todas las acciones que una comunidad debe realizar para mantener su entorno y ambiente sano, incluye mantener las aguas limpias, las basuras recogidas y las materias fecales lejos de la comunidad y en un sitio seguro" (Pimienta Gómez, 2001).

La OMS estimó en el año de 2015 que 68\% de la población mundial utiliza en la actualidad una instalación de saneamiento mejorada, sin embargo, se estima que 2400 millones de personas en todo el mundo no tienen acceso a instalaciones de saneamiento mejoradas, de las cuales 946 millones defecan al aire libre.

En Colombia las cifras no se apartan de las categorías mundiales, el informe de cumplimiento de los Objetivos de Desarrollo del Milenio nos muestra cómo nuestro país aún no logra garantizar el acceso a este servicio a toda la población, especialmente en las zonas campesinas y las localidades apartadas de las cabeceras municipales son las más afectadas por esta situación: "Por otra parte, la proporción de la población con acceso a alcantarillado es superior al $90 \%$ en zonas urbanas, pero en zonas rurales el dato de acceso a alcantarillado y soluciones alternativas se reduce a cerca de 70\%." (PNUD, 2015).

Al igual que el derecho al acceso al agua potable, el saneamiento básico también constituye un derecho fundamental, aunque sea en conexidad con este; puesto que, para desarrollarnos como seres individuales y colectivos el Estado debe garantizar un ambiente sano, propugnando por medidas anticipatorias de riesgos y daños en materia ambiental (Vargas-Chaves, 2015), con el fin de garantizar el derecho a la salud, principalmente la de los niños, que generalmente, es la más afectada por la ausencia de tratamiento de las aguas residuales; y que garantice una vida digna y adecuada.

Esto implica que los gobiernos locales y nacionales, sigan trabajando en la consecución de este derecho, que por años ha sido vulnerado, especialmente a las comunidades rurales, que no gozan de un sistema adecuado de alcantarillado, por ende, sus derechos fundamentales también afectados. 


\section{El Estado Social de Derecho y su responsabilidad en la prestación de los servicios Públicos de Acueducto y Alcantarillado}

El servicio público obedece a uno de los quehaceres diarios del Estado Social de Derecho, el cual debe garantizar la prestación efectiva de los servicios públicos, contribuyendo con el bienestar general y el mejoramiento de la calidad de vida de la población, entendidos de esta manera desde la concepción de nuestra carta política en 1991, de acuerdo con lo establecido en el Título XII, Capítulo 5 "De la finalidad social del Estado y de los servicios públicos", en donde el constituyente estableció el objetivo fundamental de la actividad estatal, la solución de las necesidades insatisfechas de salud, educación, saneamiento ambiental y agua potable.

Este es el núcleo del llamado Estado Social de Derecho, el cual ha sido proclamado en nuestro texto constitucional en el Artículo Primero, de donde provienen las garantías hacia el bienestar social de todos los asociados.

Maldonado Gómez indica que en la reforma que sufrió Colombia en el año 1936 se hablaba ya del Estado Social de Derecho, sin embargo, es solo hasta 1991 cuando se establece esta con total claridad, llevando consigo el cumplimiento de la función social por parte de los servidores públicos, quienes deben acatar la constitución y los valores en ella promulgados, dando cumplimiento a los compromisos en materia económica, social y política, garantizando ante todo la dignidad humana (Maldonado Gómez, 2010).

El concepto de servicio público, fue descrito en el Código Sustantivo de Trabajo mediante el decreto 753 de 1956 donde se estableció la prohibición de huelga en los servicios públicos, indicando con esto que

1 Maldonado Gómez, Tomas. La noción de servicio público a partir de la concepción de Estado Social de Derecho. Actualidad Jurídica. 2010. Pág. 54. En Colombia se habló por primera vez del Estado social de derecho en la reforma de 1936, en la cual se menciona la función social de los derechos, pero es en la Constitución de 1991 donde se deja claro el cambio de Estado de derecho a Estado social de derecho, como producto, entre otras cosas, de que algunos servidores públicos justificaban la violación de derechos y libertades en pro de la protección de las instituciones jurídicas. El concepto de Estado social de derecho ordena no solamente cumplir con ciertas funciones sino también producir unos efectos dentro de la comunidad, desde el punto de vista de las necesidades concretas. Esto incluye un compromiso con la realidad en los campos: económico, político y social. No 
se considera servicio público: "Toda actividad organizada que tienda a satisfacer necesidades de interés general en forma regular y continua, de acuerdo con un régimen jurídico especial, bien que se realice por el Estado directa o indirectamente, o por personas privadas".

Y en parágrafo seguido, indica que dentro de las actividades denominadas servicio público se hallan las prestadas por las empresas de acueducto y las de todos los servicios de la higiene y aseo de las poblaciones.

Este servicio público ha sido determinado por la constitución en su artículo 56 como "servicio público esencial", de donde emana su especial protección y la labor del Estado en propender a que la comunidad en general goce de los mismos, para lo cual, de forma eficiente y planificada, deberá disponer de los recursos, destinando el presupuesto y las acciones necesarias para garantizarlo.

Cuando nos referimos a la categoría de servicio público, encontramos inmersos a los Servicios Públicos Domiciliarios, los cuales han sido regulados por la Ley 142 de 1994, ley que propende a la regulación de los servicios públicos domiciliarios y por la intervención Estatal, incluyendo los servicios de acueducto, alcantarillado, aseo, energía eléctrica, distribución de gas combustible, telefonía [fija] pública básica conmutada y la telefonía local móvil en el sector rural. Los servicios públicos domiciliarios presentan unos rasgos fundamentales descritos por la jurisprudencia de la Corte Constitucional (sentencia SU 1010, 2008) del siguiente modo:

De conformidad con el artículo 365 de la Carta, el servicio público domiciliario puede ser prestado de manera directa o indirecta por el Estado, por comunidades organizadas o por particulares, manteniendo este la regulación, el control y la vigilancia sobre los mismos; b)Tiene un "punto terminal" en las viviendas o en los sitios de trabajo de los usuarios, el uso de cierta cosa"; c) Está destinado a satisfacer las necesidades básicas de las personas en concreto y de manera directa, atendiendo a las reales circunstancias fácticas en las que se encuentra. Así, se trata de aquellos servicios que tienden a satisfacer las necesidades más esenciales de la población y que se reciben directamente en los hogares o lugares de trabajo

sobra decir que es la dignidad humana el fundamento de este Estado. 
de las personas. Por esa razón, constituyen instrumentos que permiten asegurar la realización de los fines del Estado Social de Derecho, al encontrar una relación inescindible entre estos y la satisfacción de necesidades que comprometen de manera directa derechos de rango constitucional y la posibilidad de garantizar una existencia en condiciones dignas de todos los habitantes.

También la Superintendencia de Servicios Públicos Domiciliarios, institución descentralizada de carácter técnico, con personería jurídica, autonomía administrativa y patrimonial, que tiene funciones de inspección, vigilancia y control de las empresas prestadoras de los servicios domiciliarios. En la octava edición de su revista "Régimen Básico" ha indicado el sentido de los servicios públicos domiciliarios y su real alcance: "La razón de ser de los servicios públicos domiciliarios está en atender las necesidades básicas de la población, en generar bienestar, en promover la salud pública y en aumentar la productividad en general".

La Corte Constitucional se ha referido en su sentencia de T 740 de 2011 (Corte Constitucional, sentencia T 740/11), a los compromisos del Estado en la satisfacción de los servicios públicos domiciliarios, en especial atención al acceso efectivo al agua potable:

La obligación de cumplir está encaminada a que el Estado realice acciones positivas con el fin de facilitar, proporcionar y promover la plena efectividad del derecho por medio de medidas legislativas, administrativas, presupuestarias y judiciales, que posibiliten a los individuos y comunidades el disfrute del derecho al agua potable e impone al Estado que adopte medidas positivas que permitan y ayuden a los particulares y las comunidades a ejercer el derecho al agua, tome medidas para que se difunda información adecuada sobre el uso higiénico del agua, la protección de las fuentes de agua y los métodos para reducir los desperdicios de agua y garantice el acceso a una cantidad suficiente salubre, aceptable y accesible para el uso personal y doméstico de agua, en los casos en que los particulares o los grupos no están en condiciones, por razones ajenas a su voluntad, de ejercer por sí mismos ese derecho con ayuda de los medios a su disposición. 
El Estado a pesar de no ser el prestador directo de los servicios públicos domiciliarios, puesto que la Constitución Política le ha permitido realizar esta labor a través de terceros, sí le impone la carga de asegurarse de la efectiva prestación del servicio a todos los habitantes del territorio nacional -artículo 365 de la Carta Política-.

De igual manera lo ha previsto el legislador, quien plantea el segundo artículo de la ley de Servicios Públicos Domiciliarios:

2.1. Garantizar la calidad del bien objeto del servicio público y su disposición final para asegurar el mejoramiento de la calidad de vida de los usuarios; 2.2. Ampliación permanente de la cobertura mediante sistemas que compensen la insuficiencia de la capacidad de pago de los usuarios; 2.3. Atención prioritaria de las necesidades básicas insatisfechas en materia de agua potable y saneamiento básico; 2.4. Prestación continua e ininterrumpida, sin excepción alguna, salvo cuando existan razones de fuerza mayor o caso fortuito o de orden técnico o económico que así lo exijan; 2.5. Prestación eficiente; 2.6. Libertad de competencia y no utilización abusiva de la posición dominante.

Estos preceptos constituyen los principios generales de la ley de servicios públicos; dan cuenta de los lineamientos que el Estado debe perseguir con el ánimo de garantizar la cobertura a toda la población, el acceso efectivo; solucionando las necesidades básicas insatisfechas de salud, educación, de saneamiento ambiental y de agua potable, asegurando la calidad en la prestación de los servicios públicos domiciliarios, estableciendo los criterios de costos, solidaridad y redistribución del ingreso que deben caracterizar el régimen tarifario de los servicios públicos, con el propósito de dar cumplimiento a los fines del Estado Social de Derecho.

El servicio Público Domiciliario de Acueducto, denominado también servicio público domiciliario de agua potable, corresponde a la distribución municipal de agua apta para el consumo humano, incluida su conexión y medición (Superintendencia de Servicios Públicos Domiciliarios, 2013) y el Servicio de Alcantarillado, sistema conjunto de obras para la recolección, conducción y disposición final de las aguas residuales y de las aguas lluvias (Superintendencia de Servicios Públicos, 2014). 
De acuerdo a lo establecido en el contrato de prestación de Servicios Públicos, las empresas prestadoras de servicios no solo deben garantizar el servicio continuo, sino la calidad del mismo, con lo cual el agua debe ser limpia, apta para el consumo humano, porque sus características físicas, químicas y microbiológicas así lo determinan. Se han regulado las actividades relacionadas con la calidad del agua para consumo humano mediante el Decreto 475 de 1998, que estableció normas técnicas sobre las características organolépticas, físicas, químicas y microbiológicas del agua.

También se ha creado un sistema de protección y control de la calidad del agua definido por el decreto 1575 de 2007, que describe las características, instrumentos básicos y frecuencias del sistema de control y vigilancia mediante la resolución 2115 de 2007. Esta última, especifica los requisitos técnicos para calcular el Índice de Riesgo para el Consumo Humano (IRCA), el cual indica el grado de riesgo de enfermedades relacionadas con el incumplimiento de las características físicas, químicas y microbiológicas.

\section{Tratamiento jurisprudencial}

La constitución colombiana a pesar de reconocer la importancia del acceso agua y del saneamiento básico para todos los habitantes, en alguno de sus artículos constitucionales, no proclamó el derecho al agua como un derecho individual y fundamental:

Artículo 49. La atención de la salud y el saneamiento ambiental son servicios públicos a cargo del Estado. Se garantiza a todas las personas el acceso a los servicios de promoción, protección y recuperación de la salud. Corresponde al Estado organizar, dirigir y reglamentar la prestación de servicios de salud a los habitantes y de saneamiento ambiental conforme a los principios de eficiencia, universalidad y solidaridad. (...) Artículo 79. Todas las personas tienen derecho a gozar de un ambiente sano. (...) Artículo 356. Los recursos del Sistema General de Participaciones de los departamentos, distritos y municipios se destinarán a la financiación de los servicios a su cargo, dándoles prioridad al servicio de salud, los servicios de 
educación, preescolar, primaria, secundaria y media, y servicios públicos domiciliarios de agua potable y saneamiento básico, garantizando la prestación y la ampliación de coberturas con énfasis en la población pobre. (...) Artículo 366. El bienestar general y el mejoramiento de la calidad de vida de la población son finalidades sociales del Estado. Será objetivo fundamental de su actividad la solución de las necesidades insatisfechas de salud, de educación, de saneamiento ambiental y de agua potable. (...)

Sin embargo, la Corte Constitucional a través de la jurisprudencia se ha permitido desarrollar y construir el "Derecho al Agua"; en sus inicios dio gran importancia al mismo, aunque en conexidad con otros derechos, como la vida, la dignidad humana, la salud, el ambiente sano, aceptando la acción de tutela, a modo de herramienta excepcional para garantizar su protección.

Posteriormente, entre los temas abordados se sostuvo la cantidad que constituye el mínimo vital del agua, ampliando la protección del mismo, en lo que respecta al servicio público y sus características, calidad, disponibilidad, regularidad y continuidad, haciendo énfasis en la responsabilidad del Estado, la progresividad del servicio a todos los habitantes del territorio nacional, especialmente los sectores históricamente vulnerados. De esta manera lo podemos observar en las siguientes sentencias.

En 1992 se reconocía el agua como fuente de vida, indicando que la falta del servicio atentaba contra el derecho fundamental a la vida de las personas, siendo así el servicio público domiciliario de acueducto y alcantarillado, un derecho constitucional fundamental, cuando se vulnera la vida de las personas, la salubridad pública o la salud, por tanto, puede ser objeto de protección a través de la acción de tutela" (Corte Constitucional, sentencia T-578/92)

En la misma medida tuteló el derecho a la vida en 1993 cuando se estaba viendo amenazada la vida de los habitantes de una población por la utilización del agua para el consumo humano en el Acueducto la "Ciénaga de Tres Esquinas", desagüe del río Bogotá (Corte Constitucional, sentencia $\mathrm{T}-232 / 93)$. 
Algunas reflexiones sobre el agua potable y el saneamiento en el marco del derecho a la salud

En igual línea versó la sentencia de 1994, en donde la Corte hace un acercamiento hacía la calidad del agua, precisando que la pureza del agua que se percibe del acueducto, es un hecho que está directamente relacionado con el ambiente sano, es por esto que, si hay un deterioro en la fuente de agua, los usuarios se hallan en un estado de indefensión y el interés colectivo se está viendo afectado, por tal razón se admite la acción de Tutela (Corte Constitucional, sentencia T523/94).

Reiterando en sentencia de 2011, que la acción de tutela es una herramienta excepcional para lograr la protección del derecho al agua, en el ámbito de la prestación del servicio público, cuando esta sea para el consumo humano domiciliario, siempre que se esté afectando otro derecho, como la vida o la salud, y será procedente para quien halle que su derecho fundamental ha sido vulnerado, a pesar de haber realizado unas mínimas actuaciones ante la empresa que presuntamente lo ocasiona (Corte Constitucional, Sentencia T279/11).

En este mismo año se pronuncia en torno al derecho al agua, considerando el concepto que estableció el Comité de Derechos Económicos, Sociales y Culturales: "el derecho de todos de disponer de agua suficiente, salubre, aceptable, accesible y asequible para el uso personal o doméstico". Indicando que en el ordenamiento jurídico colombiano el agua se presenta en dos vertientes, una viene a ser el derecho fundamental, la otra, en tanto que es un servicio público (Corte Constitucional, sentencia T 740/11).

En otro de sus pronunciamientos hallamos que al hacer un estudio del derecho fundamental al agua, bajo el ordenamientojurídico, lajurisprudencia constitucional, el Pacto Internacional de Derechos Económicos Sociales y Culturales, así como las recomendaciones del Comité de Derechos Económicos Sociales y Culturales, encuentra la especial protección que debe garantizarse a los sujetos que tradicionalmente han sido excluidos, en cuanto al goce de un mínimo de agua apta para el consumo, 50 litros, con el cual puedan satisfacer sus necesidades básicas domiciliarias, prevenir los problemas de salud y en general servicios sanitarios (Corte Constitucional, sentencia T242/13).

La Corte Constitucional ha considerado que el derecho al agua es un derecho fundamental, que merece una amplia protección y unas garantías mínimas de disponibilidad, accesibilidad, calidad y no discriminación en 
la distribución, es por esto que el Estado debe asegurar un mínimo vital de agua en condiciones adecuadas, disponibles, regulares y continuas, generando planes de acción que garanticen progresivamente su goce efectivo (Corte Constitucional, sentencia T 028/14).

También indica que en virtud del bloque de constitucionalidad, "El derecho al Agua" es incorporado al ordenamiento jurídico interno para complementar el capítulo de derechos fundamentales, precisando con ello que una entidad prestadora del servicio público vulneró los derechos fundamentales de un grupo familiar, en la medida en que no realizó las actividades necesarias para garantiza la cantidad mínima esencial de agua que requieren a diario ni había previsto ninguna forma de distribución que garantizara el contenido mínimo (Corte Constitucional, sentencia T790/14).

En la misma medida en el año de 2015, la Corte Constitucional ordenó al Acueducto Metropolitano de Bucaramanga suministrar, por lo menos, 50 litros de agua apta para el consumo humano a una familia con tres menores de edad, a quienes les fue suspendido el servicio por estar en proceso de legalización de predio y no contar con el boletín de nomenclatura urbana, la licencia de construcción, el certificado de libertad y tradición (Corte Constitucional, sentencia T641/15).

En este mismo año, también la Corte se ha pronunciado con respecto al Derecho al Servicio de Alcantarillado y su protección excepcional por vía de tutela, considerándolo cuando su falta o ineficiente prestación, por negligencia de la administración, genere perjuicios de manera evidente a la dignidad humana, la vida y la salud. Ya sea por su ausencia o mala prestación, cuando quiera que perjudique de manera notoria derechos fundamentales, a pesar de que exista otro medio de defensa judicial (Corte Constitucional, sentencia T 042 de 2015).

Seguidamente, se ha pronunciado acerca de la dimensión objetiva del derecho al agua como derecho fundamental, de donde emana su poder vinculante frente a todos los poderes públicos, guiando así las decisiones de todas las autoridades, pues su respaldo se halla en el texto constitucional, y en su dimensión subjetiva, puede ser reclamado ante las instancias judiciales en casos de vulneración, ya sea por parte del Estado como por 
Algunas reflexiones sobre el agua potable y el saneamiento en el marco del derecho a la salud

parte de particulares, principalmente en los casos en que esta es para el consumo humano (Corte Constitucional, sentencia T 131/16).

Finalmente, ha advertido que la acción de tutela en materia general, es improcedente cuando busca el amparo de derechos colectivos, sin embargo, de manera excepcional puede ser procedente si ante esta vulneración de derechos colectivos convergen derechos fundamentales (Corte Constitucional, sentencia 139/16).

\section{Perspectiva internacional}

Desde la Declaración Universal de los Derechos Humanos, proclamada por la Asamblea General de las Naciones Unidas en París el 10 de diciembre de 1948 en su Resolución 217 A (III), la necesidad de garantizar a todos los miembros de la familia humana el reconocimiento de sus derechos, los cuales dignifican al hombre y deben ser reconocidos por ser de carácter universal, irrenunciable, imprescriptible, inalienable e indivisible, es por esto que la Declaración vislumbraba la necesidad de que los Estados velaran por el bienestar y los servicios sociales necesarios para garantizar un "nivel de vida adecuado" de esta manera indicó el Artículo 25:

1. Toda persona tiene derecho a un nivel de vida adecuado que le asegure, así como a su familia, la salud y el bienestar, y en especial la alimentación, el vestido, la vivienda, la asistencia médica y los servicios sociales necesarios; tiene asimismo derecho a los seguros en caso de desempleo, enfermedad, invalidez, viudez, vejez y otros casos de pérdida de sus medios de subsistencia por circunstancias independientes de su voluntad.

Ante la imperiosa de necesidad de seguir trabajando por la obligatoriedad del acceso a los servicios sociales necesarios para un nivel de vida adecuado, en la Pacto Internacional de Derechos Económicos, Sociales y Culturales, adoptado por la Asamblea General en su resolución 2200 A (XXI), de 16 de diciembre de 1966, y el cual entró en vigor el 3 de enero de 1976, exhorta a los Estados a reconocer el derecho que tienen todos los individuos a acceder a un nivel de vida adecuado: 
Artículo 17. Los Estados Partes en el presente Pacto reconocen el derecho de toda persona a un nivel de vida adecuado para sí y su familia, incluso alimentación, vestido y vivienda adecuados, y a una mejora continua de las condiciones de existencia. Los Estados Partes tomarán medidas apropiadas para asegurar la efectividad de este derecho, reconociendo a este efecto la importancia esencial de la cooperación internacional fundada en el libre consentimiento.

Posterior a estas proclamaciones, la Asamblea General de la Organizaciones de Naciones Unidas en sus resoluciones reitera la importancia del acceso a servicios que permitan el bienestar y una calidad de vida adecuada, según la Resolución 54/175 de 17 de diciembre de 1999, relativa al derecho al desarrollo, recalcando este como un derecho humano inalienable.

La Resolución 55/196 de 20 de diciembre de 2000 proclamó el año 2003 como el Año Internacional del Agua Dulce, haciendo un llamado a los Estados Miembros, a las organizaciones nacionales e internacionales y a todos los grupos de interés para que aprovecharan la iniciativa e iniciaran acciones a nivel local, nacional, regional o internacional con el objeto de aumentar la toma de conciencia sobre la importancia del agua dulce.

Posteriormente con la resolución 58/217, de 23 de diciembre de 2003 se hace la proclamación del Decenio Internacional para la Acción: "El agua, fuente de vida" (2005-2015), resaltando que el agua es fundamental para el desarrollo sostenible, la salud y el bienestar humano, de igual modo, para la integridad del medio ambiente, la lucha contra la pobreza y el hambre.

En el año de 2006, con la expedición de la resolución 61/192 en la que se proclamó el 2008 como el Año Internacional del Saneamiento, buscando servir de estímulo a los países miembros y otras organizaciones internacionales para emprender iniciativas globales que den prioridad al saneamiento, a su vez, intentando redoblar los esfuerzos para conseguir el objetivo de desarrollo del Milenio para 2015, abasteciendo a la población que carece de acceso a agua potable y al saneamiento básico.

Fue en el año 2010, con la resolución N 64/292, aprobada por la Asamblea General, que se reconoció el abastecimiento al agua y al saneamiento básico, como un derecho humano, por tanto, todas las personas 
tienen derecho a "disponer de forma continuada de agua suficiente, salubre, físicamente accesible, asequible y de una calidad aceptable, para uso personal y doméstico" (Asamblea General de las Naciones Unidas, 2010).

Posteriormente, se proclamó el 2013 como el Año Internacional de Cooperación de Agua, preocupados porque el cumplimiento del objetivo, de reducir a la mitad el porcentaje de personas sin acceso al agua potable y a servicios de saneamiento, ha sido de forma lenta y desigual; entendiendo que el agua es un tema que requiere atención en todos, se hace un llamado hacia la cooperación para lograr los Objetivos del Milenio a fin de garantizar la "seguridad hídrica" y el futuro sostenible de las comunidades. (Asamblea General de las Naciones Unidas, 2011).

La ONU indica que ha sido el 2015 el año crítico para la agenda internacional del agua y el saneamiento. Puesto que, con los resultados de los Objetivos del Milenio se trabajó en la formulación de los Objetivos de Desarrollo Sostenible de una forma específica para el agua y el saneamiento, se intenta de forma ambiciosa lograr el acceso universal a los servicios de acueducto y alcantarillado, mejorar la gestión de los recursos hídricos, de forma eficiente, de calidad y reducción el riesgo de desastres (ONU, 2015a).

\section{Conclusiones}

Colombia, de acuerdo con el texto constitucional, está consagrado como Estado Social de Derecho, dentro de sus fines esenciales está el propender a los derechos sociales fundamentales, razón por la cual debe trabajar arduamente por la consecución de los servicios públicos de acueducto y alcantarillado para todos los habitantes, pues a pesar de haber alcanzado importante logros en materia del agua, "aún quedan retos importantes por adelantar, pues los avances no se han presentado de manera homogénea a lo largo y ancho del territorio nacional" (PNUD, 2015).

El agua ha sido reconocida por nuestra jurisprudencia como un elemento fuente de vida, esencial para el desarrollo de los derechos fundamentales, que en concordancia con los tratados internacionales y a través del bloque de constitucionalidad, entiende que el acceso al agua, es un derecho humano, y en conexidad con este y con otros derechos 
fundamentales han tutelado el derecho al saneamiento básico, con el fin de proteger a los más vulnerados.

A su vez, a nivel internacional el acceso al agua ha sido proclamado como derecho humano, adelantando todos los esfuerzos, programas y acciones necesarios para ratificar su importancia en la vida de los seres humanos, intentando trabajar en cooperación para lograr su abastecimiento efectivo, su protección y garantía en la esfera del consumo humano.

Por último, no debe dejarse a un lado que el saneamiento básico ha sido reconocido como un derecho asociado estrechamente al derecho al agua, producto del resultado de compromisos y declaraciones internacionales, especialmente los Objetivos de Desarrollo del Milenio, y por supuesto los actuales Objetivos de Desarrollo Sostenible, por ser vitales para la dignidad humana, la salud y el medio ambiente.

\section{Referencias}

Alto Comisionado de las Naciones Unidas para los Derechos Humanos. (Marzo, 2011). El derecho al Agua. Génova: Naciones Unidas.

Asamblea General de las Naciones Unidas. (2010). Resolución N. 64/292. Resolución aprobada el 28 de julio de 2010.

Asamblea General de las Naciones Unidas. (2011). Resolución A/ RES/65/154.

Corte Constitucional. (1992). Sentencia T-578. [M. P. Alejandro Martínez Caballero].

Corte Constitucional. (1993). Sentencia T-232. [M. P. Alejandro Martínez Caballero].

Corte Constitucional. (1994). Sentencia T-523. [M. P. Alejandro Martínez Caballero].

Corte Constitucional. (2011). Sentencia T-279. [M. P. Luis Ernesto Vargas Silva].

Corte Constitucional. (2011). Sentencia T-740. [M. P. Humberto Antonio Sierra Porto].

Corte Constitucional. (2013). Sentencia T-242. [M. P. Luis Ernesto Vargas Silva]. 
Algunas reflexiones sobre el agua potable y el saneamiento en el marco del derecho a la salud

Corte Constitucional. (2014). Sentencia T-028. [M. P. María Victoria Calle Correa].

Corte Constitucional. (2014). Sentencia T-790. [M. P. Jorge Ignacio Pretelt Chaljub].

Corte Constitucional. (2015). Sentencia T-042. [M. P. Jorge Iván Palacio Palacio].

Corte Constitucional. (2015). Sentencia T-641. [M. P. Alberto Rojas Ríos].

Corte Constitucional. (2016). Sentencia T-131. [M. P. Jorge Ignacio Pretelt Chaljub].

Corte Constitucional. (2016). Sentencia T-139. [M. P. Jorge Iván Palacio Palacio].

Guerrero Legarreta, M. (2012). El agua (Vol. Primera Edición Electrónica). México D.F.: Fondo de Cultura Económica.

Juzgado Doce Administrativo del Circuito de Cartagena. (19 de 09 de Sentencia 248 de 2011). 13-001-23-31-013-2009-00265-01.

Maldonado Gómez, T. (2010). La noción de servicio público a partir de la concepción de Estado Social de Derecho. Actualidad Jurídica, 54.

OMS/UNICEF (2015). Informe 2015 del Programa Conjunto OMS/UNICEF de Monitoreo. Organización Mundial de la Salud- Unicef.

ONU (2010). Resolución 64/292, Sexagésimo cuarto período de sesiones. Asamblea General de las Naciones Unidas 28 de 07 de 2010.

ONU (Noviembre de 2002). Observación General No. 15. El derecho al agua. Comité de Naciones Unidas de Derechos Económicos, Sociales y Culturales.

ONU. (1976). Pacto Internacional de Derechos Económicos, Sociales y Culturales. Resolución 2200 A (XXI), Asamblea General.

Organización de las Naciones Unidas. (2010). El derecho humano al agua y al saneamiento. Oficina de Naciones Unidas de apoyo al Decenio Internacional para la Acción "El agua es fuente de vida" 2005-2015 (pág. 5). Zaragoza - Espala: ONU.

Organización de las Naciones Unidas. (2015a). Una historia de 10 años: "El Agua, Fuente de Vida" 2005-2015. Programa de ONU-Agua para la Promoción y la Comunicación en el marco del Decenio (UNWDPAC), Fundación Aquae. 
Organización de las Naciones Unidas. (2015b). El derecho al agua y el saneamiento básico. Nota para medios. Zaragoza, España: Oficina de las Naciones Unidas. Recuperado de https://www.un.org/spanish/waterforlifedecade/pdf/human_right_to_water_and_sanitation_ media_brief_spa.pdf

Organización Mundial de la Salud. (11 de 2016). Who. Recuperado el 06 de 2017, de Agua, nota descriptiva: http://www.who.int/mediacentre/factsheets/fs391/es/

Organización Mundial de la Salud. (2006). Hoja informativa, Número 2, Celebración del Decenio Internacional para la Acción «El agua, fuente de vida 2005-2015». Ginebra: OMS.

Organización Mundial de Salud. (02 de 2017). OMS. Recuperado el 15 de 06 de 2017, de http://www.who.int/water_sanitation_health/water-quality/es/

Pimienta Gómez, L. (2001). Saneamiento básico, salud e higiene. Riohacha: Quebrecor Bogotá.

PNUD. (2015). Objetivos de desarrollo del Milenio. El PNDU en Colombia Informe 2015. Bogotá D.C.; Colombia: Programa de las Naciones Unidas para el Desarrollo; Nuevas Ediciones S.A.

Programa de las Naciones Unidad para el Desarrollo. (2006). Informe sobre Desarrollo 2006. Más allá de la escasez: Poder, pobreza y la crisis mundial del agua. Nueva York: PNUD.

Rodríguez, G., Lozano Acosta, C., \& Gómez Rey, A. (2012). La protección jurídica del agua en Colombia. Bogotá D.C.: Grupo Editorial Ibañez. Rodríguez, G.A., \& Vargas-Chaves, I. (2014) Políticas de igualdad e intereses colectivos. Bogotá: Grupo Editorial Ibáñez.

Superintendencia de Servicios Públicos Domiciliarios. (2013). La Calidad del Agua. Bogotá D.C.: Imprenta Nacional de Colombia.

Superintendencia de Servicios Públicos. (2014). Superservicios. Obtenido de http://www.superservicios.gov.co/eng/content/download/5730/51364/file/Glosario-Delegada-AAA-jul-14.pdf 


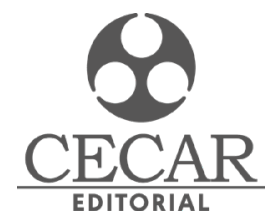

Edición digital

Derecho y salud: Debates contemporáneos

Abril de 2020

Sincelejo, Sucre, Colombia 